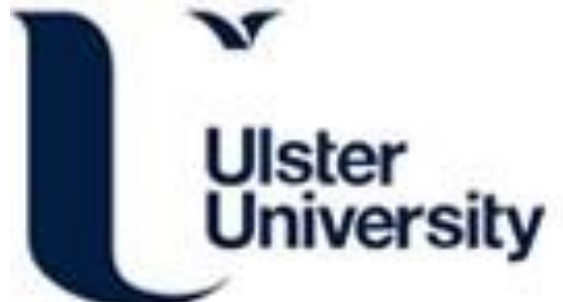

\section{Contrasting Levels of Accuracy in Command Interaction Sequences for a Domestic Brain-Computer Interface Using SSVE}

Ware, M., McCullagh, PJ., McRoberts, A., Lightbody, G., Nugent, CD., McAllister, HG., Mulvenna, M., Thomson, E., \& Martin, S. (2010). Contrasting Levels of Accuracy in Command Interaction Sequences for a Domestic Brain-Computer Interface Using SSVE. In Biomedical Engineering Conference (CIBEC), 2010 5th Cairo International (pp. 150-153). IEEE Computer Society. https://doi.org/10.1109/CIBEC.2010.5716040

Link to publication record in Ulster University Research Portal

\section{Published in:}

Biomedical Engineering Conference (CIBEC), 2010 5th Cairo International

Publication Status:

Published (in print/issue): 01/12/2010

DOI:

10.1109/CIBEC.2010.5716040

\section{Document Version}

Publisher's PDF, also known as Version of record

\section{General rights}

Copyright for the publications made accessible via Ulster University's Research Portal is retained by the author(s) and / or other copyright owners and it is a condition of accessing these publications that users recognise and abide by the legal requirements associated with these rights.

\section{Take down policy}

The Research Portal is Ulster University's institutional repository that provides access to Ulster's research outputs. Every effort has been made to ensure that content in the Research Portal does not infringe any person's rights, or applicable UK laws. If you discover content in the Research Portal that you believe breaches copyright or violates any law, please contact pure-support@ulster.ac.uk. 


\title{
Contrasting Levels of Accuracy in Command Interaction Sequences for a Domestic Brain-Computer Interface Using SSVEP
}

\author{
Melanie P. Ware, Paul J. McCullagh, Alexander McRoberts, Gaye Lightbody, Chris Nugent, \\ Gerry McAllister, Maurice D. Mulvenna, Eileen Thomson and Suzanne Martin
}

\begin{abstract}
Providing a usable domestic brain-computer interface (BCI) for persons with disabilities requires that the development team ensure ease of interaction for all the potential users. To do this for individuals with complex needs often requires that an approach is tailored to a specific user. However, in developing a domestic BCI it is necessary to consider the provision of an application which hides the complexity of the underlying science from the user whilst delivering acceptable levels of interaction for many. This is not an unusual circumstance in the realm of assistive technology. We present a cohesive test suite which allows the development team to assess what constitutes an acceptable level of accuracy in a four-way command interface using steady-state visually evoked potentials (SSVEP). It also facilitates a uniform assessment of the level of accuracy achieved by a specific user operating a BCI and provides a means of contrasting and selecting performance parameters in order to enhance user performance.
\end{abstract}

\section{INTRODUCTION}

B RAIN-COMPUTER interfaces 'electroencephalographic (EEG) activity or cortical single-neuron activity to control cursor movement, select letters or icons or operate neuroprostheses.' [1]. There are many papers published giving an account of brain-computer interfaces which allow a user to control a single specific device or application [2]-[7]. The ability to use the same underlying BCI application in order to control multiple devices has also been identified [8]. The ability of a BCI to provide individuals suffering from neurophysiological disorders with a means to control their environment and communicate is cited as a motive behind many research initiatives [6], [8]-[12].

It is the underlying objective of the BRAIN project to combine these factors by providing a $\mathrm{BCI}$ for use in a domestic environment to control multiple domotic devices and applications for individuals suffering from a variety of

Manuscript received June 29 2010. This work was supported in part by the European Commission's ICT for Inclusion Unit under Grant EU FP72007-224156: BRAIN.

M. P. Ware (corresponding author) is with the School of Computing and Mathematics, University of Ulster, Jordanstown, BT37 0QB. United Kingdom. phone: 0044 (0) 28 9036-6045; fax: 0044 (0) 28 9036-6216; email: m.p.ware@ulster.ac.uk.

P. J. McCullagh, A. McRoberts, G. Lightbody, Chris Nugent, Gerry McAllister and Maurice Mulvenna are also with the University of Ulster, details above.

Eileen Thomson is with the Cedar Foundation, 31 Ulsterville Avenue, Belfast, Co. Antrim, BT9 7AS United Kingdom

Suzanne Martin is with the Health \& Rehabilitation Sciences Research Institute (HRSRI), School of Health Sciences, University of Ulster, Jordanstown Campus, Shore Road, Newtownabbey, Co. Antrim, BT37 0QB, United Kingdom. underlying conditions [13]. To this end a ubiquitous intuitive graphical user interface (IGUI) employing a fourway command mechanism has been developed [14], [15]. The interface facilitates the user by allowing navigation between the rooms of a home in order to enact commands on a variety of devices. Currently it has been demonstrated that this interface can be operated by using one of three BCI signal acquisition/processing applications available to the research team. All three offer interaction via detecting the user's reaction to flickering visual stimuli, SSVEP. They include an application dedicated to the use of high-frequency stimuli [16] one originally based upon low-frequency stimuli [17] and an openSource application [18]. Other forms of interaction based upon different BCI paradigms are under development and can also be accommodated by the IGUI. This includes monitoring for voluntary imagined movement. By offering multiple approaches it is intended to facilitate as many users as possible, allowing the user to select the modality of interaction best suited to their individual circumstances or to switch paradigms, in order to prolong tolerance of interaction during a single session. This may be applicable should the user become fatigued by the constant flicker of SSVEP or by the concentration required for imagined movement.

When providing a user interface there are many factors, which contribute to the success of the application and the users' willingness to take up the technology and sustain it use over time. An application needs to meet its stated objectives. Major factors concerning the perceived success of BCI applications concern 'the ability to take sensitive and reliable measures of brain activity' and to 'harness the measures in order to control interactive systems' [19]. From a users perspective we can ask, 1) What constitutes reliable measures of brain activity? and 2) What constitutes the ability to control an interactive system? Many papers on BCI and specifically in this context SSVEP provide measures of performance. Typically these take many forms: communication bit rate and operating frequency [16], robustness to false positives [20], average bits per minute [17], average error rate [20] and accurate classification over time [17]. Some of these measures focus upon single underlying indicators, such as the ability of the user to respond to stimuli Figure 1. However, whilst providing the foundations for a successful system these indicators may not always translate into performance measures which express the users perception of the success or otherwise of the application. In this instance a good SSVEP response did not translate into good command classification when four 
frequencies of flicker were combined.

Other work in the realm of assistive technology has focused upon the user experience [21] and performance in relation to input modalities. It can be argued that for the user the single overriding performance measure is of command classification accuracy within a reasonable timescale [11]. This is particularly significant when placed within the context of BCI where commonly applications are not wholly accurate: 70\% [8], 68-77\% [12] 97.5\% [17] and the operation of an interface may require a trade-off between technological factors and usage patterns.

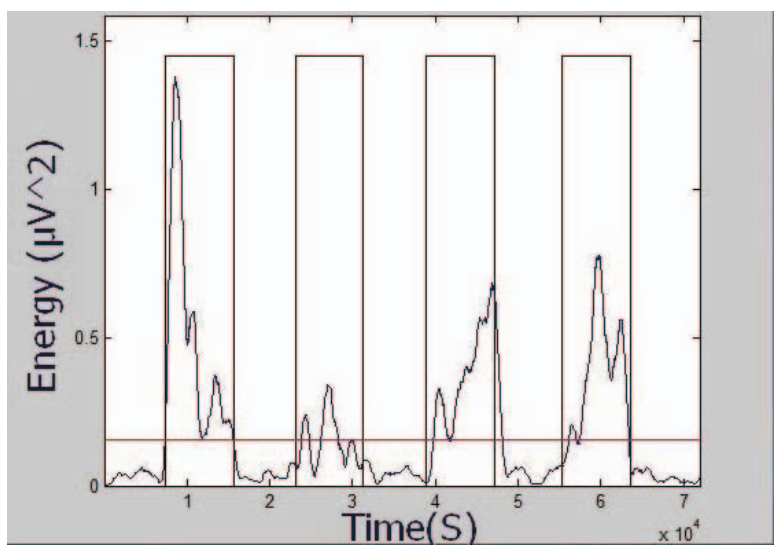

Figure 1: User's SSVEP response to visual stimuli at $34 \mathrm{~Hz}$.

In attempting to answer what constitutes a reliable measure we have provided a test application which focuses upon the user's perception of reliability. Similarly, when attempting to answer the question - what constitutes the ability to control an application, measures of command classification performance are harvested as a user interacts with a test tool. This paper details the test suites employed, section II, an empirical investigation based upon five user, section III, and our conclusions and future work, section IV.

\section{BCI USER TEST APPLICATIONS}

The user interface devised by the BRAIN project adopts the suggested modular approach to BCI systems [22] which is enshrined in BCI2000 [10]. It employs a minimum communication interface between the BCI application which acquires and classifies EEG signals and the interfaces or devices that the user operates. It is based upon passing UDP packets between a specific BCI application and the IGUI, each packet containing a single command classification. This architectural model facilitates the substitution of test applications when detecting items of interest concerning the user's personal interaction model Figure 2.

\section{A. BCI Accessibility Assessment}

As yet, the BCI community has not established a minimum level of tolerated accuracy in the command interface. This test is designed to provide an indication of a minimum level of accuracy for a user when using a four-way command interface designed for the purpose of menu navigation. There are two measures taken during the testing procedure. These are used to suggest: a) A minimum desirable level of accuracy in a command mechanism, and b) A minimum acceptable level of accuracy in a command interface when used by a motivated and informed user.

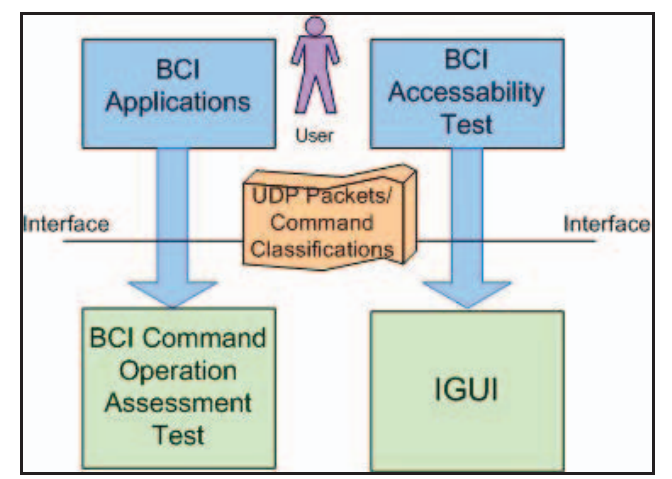

Figure 2: BCI User Test Applications in the Context of the BRAIN Systems Architecture

The BCI accessibility assessment uses a mouse-controlled interface to provide input to the IGUI, Figure 3. The user is asked to achieve navigational tasks by the tester who issues high level navigational prompts. Typically, 'Go to the dining room and turn on the light'. The test tool is designed to issue incorrect commands to the IGUI on an increasing scale. Concerning test a.), initially the user is unaware that inaccuracies will be generated. In the first instance their ability to perceive and tolerate these inaccuracies prior to exhibiting discouragement is measured. The result is presented as a percentage score of inaccurate commands in relation to the total command set. This is used to represent an initial level toleration to an inaccurate interface. In test b.), the user is asked to repeat the test once more. This time knowingly tolerating and accommodating the inaccurate interface until they judge that any meaningful navigation becomes impossible. This test is performed a number of days after the initial test. Again the score is represented as a percentage of inaccurate commands to the total command set. This measure is used to represent the level of toleration of a user towards an interface when the user expects the interface to be inaccurate but is prepared to make an attempt. Combined the measures provide an indicator of the level of accuracy to which a user expects a system to conform.

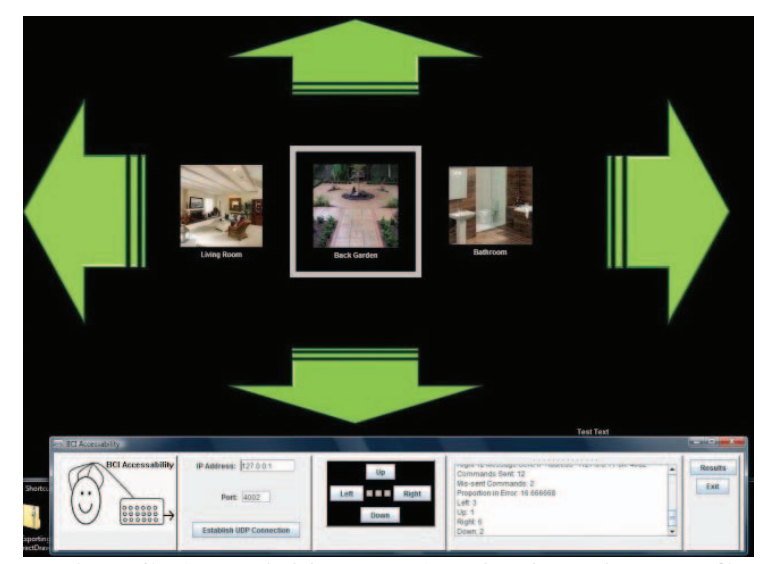

Figure 3: BCI Accessibility Test Application with the IGUI 


\section{B. BCI Command Operation Assessment}

Due to their differing underlying features various BCI applications will perform differently when used with the same user interface and operated by the same individual. Also the same BCI application will perform differently with the same user with different input parameters. To the user one of the primary performance measures is command accuracy levels combined with time to operate. This interface is designed to present a uniform four-way command interface which can interact with various BCI applications whilst harvesting user usage statistics.

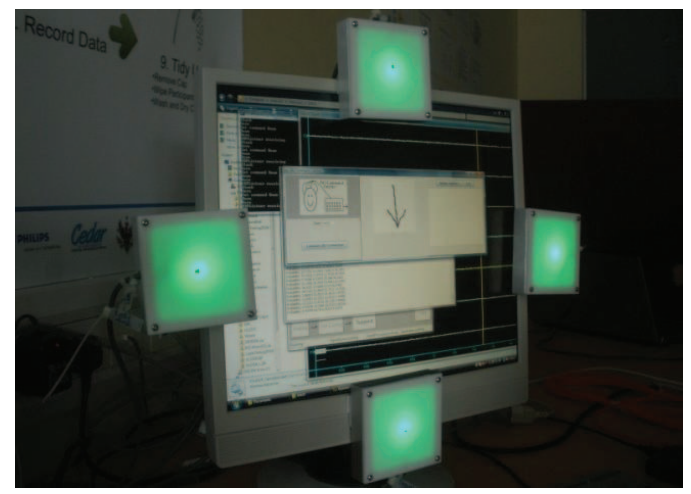

Figure 4: BCI Command Operation Assessment Test

A sequence of directional stimuli (up, down, left, right) designed to generate specified responses is determined by the tester in accordance with the requirements of the test. In this instance a test sequence is designed to encompass movement from a specific arrow to all other arrows and to include for each arrow multiple consecutive requests for the same arrow. There are 42 directional prompts. During the test the user is asked to observe the various stimuli of the sequence. The resulting command classification is recorded and the duration to complete. These measures are used as an indicator of the level of command accuracy that a user can achieve in a specific interaction sequence with a particular BCI application. The overall accuracy level is recorded as a percentage of correct interactions from the whole command set.

\section{BCI USER ASSESSMENTS}

The test suite was applied to a group of five users. This consisted of both computer literate and naive users and individuals with and without disabilities; it encompassed an age range of 25-78. All subjects participated in the BCI accessibility assessment, they then completed the command operation assessment, facilitating a contrast between user specific accuracy levels and the levels achieved using one of the BCI applications [17] with frequency values of the range $13-16 \mathrm{~Hz}$ at $1 \mathrm{~Hz}$ increments. The results for this test are presented in TABLE I. Concerning the accessibility assessment it is interesting to note that three users were less tolerant of an application, which was known to be inaccurate. Perhaps trusting the technology is significant, or, alternatively, the impact of the mis-sent command is greater in some contexts than others. With all users, they terminated the test when the application in-advertently exited. There was no significant difference in expected accuracy levels between the naive user-4, than the other users. This person used the application less confidently; however, they were methodical in their approach. They detected inaccurate commands on the second occurrence continuing operation whilst checking this impression. User expected levels of accuracy range between $74-81 \%$. Users 1 and 3 did not achieve either of their accuracy indicators. Both these users suffer from a physical disability: an acquired brain injury and cerebral palsy respectively.

TABLE I:

BCI ACCESSIBILITY REQUIREMENTS CONTRASTED TO COMMAND OPERATION ACCURACY

\begin{tabular}{lccccc}
\hline \hline Users & 1 & 2 & 3 & 4 & 5 \\
\hline $\begin{array}{l}\text { Minimum Desirable } \\
\text { \% Accuracy }\end{array}$ & 79 & 77 & 77 & 74 & 78 \\
$\begin{array}{l}\text { Minimum Acceptable } \\
\text { \% Accuracy }\end{array}$ & 81 & 81 & 76 & 77 & 77 \\
$\%$ Achieved Accuracy & 16 & 95 & 62 & 80 & 95 \\
\hline \hline
\end{tabular}

A second test was run, which focused upon a single healthy user. This test used the BCI command operation assessment utility alone. It was used to determine an optimum frequency range for a single BCI application [17], Table II. The advantage of using the test interface under these circumstances is that an objective assessment from the perspective of the user can be obtained. This remains true even when the BCI application is changed or as in this particular test, the parameters of operation are modified.

TABLE II:

BCI COMMAND OPERATION ACCURACY OBTAINED WITH DIFFERING FREQUENCY INPUTS

\begin{tabular}{lcc}
\hline \hline Range & $\begin{array}{c}\text { \% Accuracy } \\
\text { Achieved }\end{array}$ & $\begin{array}{c}\text { Time Taken } \\
\text { minutes }\end{array}$ \\
\hline $\begin{array}{l}\mathbf{1 3}-\mathbf{1 6 H z} \\
\text { with } \mathbf{1 ~ H z} \text { increments }\end{array}$ & 93 & 4 \\
$\mathbf{1 8}-\mathbf{2 4} \mathbf{~ H z}$ & 90 & 3 \\
$\begin{array}{l}\text { With } \mathbf{2 ~ H z} \text { increments } \\
\mathbf{2 6 - 3 2} \mathbf{H z}\end{array}$ & 95 & 4 \\
$\begin{array}{l}\text { With } \mathbf{2 H z} \text { increments } \\
\mathbf{3 0 - 3 6 H z} \\
\text { With } \mathbf{2 ~ H z} \text { increments }\end{array}$ & 90 & 4 \\
\hline \hline
\end{tabular}

The test demonstrated that a good SSVEP response was achieved in all cases, as all readings were above the level of accuracy indicated by every subject in the previous test. The optimum frequency appears to be in the middle/high frequency range. This is desirable as the higher rates of flicker are more easily tolerated and less likely to induce epilepsy [20]. The operational duration was broadly similar.

\section{CONCLUSIONS AND FUTURE WORK}

The BCI accessibility assessment indicates that users 
expect a high level of command accuracy from an application before considering it worthwhile. However, the performance of the test demonstrated that the context of the command inaccuracy is significant in supporting the users continued use of the application. Some users discontinued the session after inadvertently exiting the application. This suggests that strategies in the interface which support the user or attempt to detect inadvertent command sequences should be adopted. The accuracy levels reported in recent publications tend to [12], [17] conform to users expectations. Significantly, however, concerning the test of command operational accuracy, the users with disabilities did not achieve a level of operation which conformed to their specified expectations. This suggests that either the mechanisms employed in the BCI application should be tailored to their use or that this paradigm is not suited to their capabilities. This needs further investigation. The test for BCI accessibility relies upon the use of a mouse to input commands; requiring that the user has a significant degree of physical mobility or that they can communicate their wishes to a third party, thereby negating the need for a BCI. Some of the disabled users involved in the study do not currently need such assistance but contemplate possible future circumstances. Others feel that they represent a user group from whom meaningful results can be extrapolated.

The second test examining the impact of modified input parameters upon command operation performance provided a means of assessing accuracy in relation to frequency in the context of a single user. This test indicated that for this user all frequency ranges provided an acceptable level of operation, however, the frequency range $26-32 \mathrm{~Hz}$ provided the best command accuracy. Modifications to frequency ranges did not significantly impact upon time to operate. It was felt that the command operation assessment is useful when representing the final outcome of technical modifications in conjunction with a user interface.

These tests and findings illustrate that the user assessments are capable of informing the development process and thereby improving the user experience.

\section{ACKNOWLEDGMENT}

The research leading to these results has received funding from the European Community's Seventh Framework Programme under grant agreement No 224156.

\section{REFERENCES}

[1] T.M. Vaughan, W.J. Heetderks, L.J. Trejo, W.Z. Rymer, M. Weinrich, M.M. Moore, et al., "Guest Editorial. Brain-Computer Interface Technology: A Review of the Second International Meeting", IEEE Transactions on Neural Systems and Rehabilitation Engineering Vol. 11, No. 2, pp. 94-109, 2003.

[2] M. Bensch, A. A. Karim, J Mellinger, T. Hinterberger, M Tangermann, M. Bogdan, et al., "Nessi: An EEG-Controlled Web Browser for Severly Paralysed Patients", Computational Intelligence and Neuroscience, 2007, Hindawi Publishing Corporation.

[3] R. Leeb, D. Friedman, G. R. Müller-Putz, R. Scherer, M. Slater, G. Pfurtscheller, "Self-paced (Asynchronous) BCI control of a wheelchair, in virtual environments: A case study with a tetraplegic",
Computational Intelligence and Neuroscience, Apr. 2007, Hindawi Publishing Corporation.

[4] B. Blankertz, M Krauledat, G Dornhege, J. Williamson, R. MurraySmith, K-R. Müller, "A note on brain actuated spelling with the Berlin brain-computer interface", Proc. of the 4th Intl conf. on Universal access in human-computer interaction: ambient interaction, Lecture Notes in Computer Science,2007, pp759-768.

[5] E. R. Miranda, A. Brouse, "Interfacing the Brain Directly with Musical Systems: On Developing systems for making music with brain signals", Leonardo, vol 38, no 4, 2005, pp331-336.

[6] E. A. Fenton, N. L. Lewis, S.A. Wills, R. G. Radwin, J. C. Williams, "Neural Signal Based Control of the Dasher Writing System", Proc. of the $3^{\text {rd }}$. IEEE Int. Conf. Neural Engineering, Hawaii, 2007 pp366370 .

[7] S. Acharya, V Aggarwal, F. Tenore, H-C Shin, R Etienne-Cummings, M. H. Schieber, et al., "Towards a Brain-Computer Interface for Dexterous Control of a Multi-Fingered Prosthetic Hand", Proc. of the $3^{\text {rd }}$. Intl, EMBS Conf. on Neural Engineering, Hawaii, May 2007, pp200-203.

[8] J. R. Millan, "Adaptive Brain Interfaces", Communications of the $A C M I$, Vol. 46, No. 3, March 2003, pp75-80.

[9] N. Neumann, A. Kübler, "Training Locked-in Patients: A Challenge for the Use of Brain-Computer Interfaces", IEEE Trans. On Neural Systems and Rehabilitation Engineering Vol. 11, No. 2, pp169-172.

[10] G. Schalk, D. J. McFarland, T. Hinterberger, N Birbaumer, J. R. Wolpaw, "BCI2000: A General Purpose Brain-Computer Interface (BCI) System", in IEEE Trans. On Biomedical Engineering, vol. 51, no 6, Jun. 2004, pp1034-1043.

[11] L. Maggi, S. Parini, L. Piccini, G. Panfili, G. Andreoni, "A four Commnd BCI System Based on the SSVEP Protocol", Proc. of the $28^{\text {th }}$. IEEE EMBS An. Intl. Conf New York, Aug. 2006, pp1264-1267.

[12] G. Valsan, B. Grychtol, H. Lakany, B. A. Conway, "The Strathclyde brain computer interface", $31^{s t}$. Annual Intl Conf. of the IEEE EMBS, Sep. 2009, pp606-609.

[13] B. Allison, "The I of BCIs: next generation interfaces for braincomputer interface systems that adapt to individual users," in Proc. of the HCI 2009 conference, Human-Computer Interaction. Novel Interaction Methods and Techniques, July 2009, pp. 558-568.

[14] M.P. Ware, P.J. McCullagh, M.D. Mulvenna, C.D. Nugent, H.G. McAllister, and G. Lightbody. A universal command structure for multiple domotic device interactions. in Proc. of the TOBI (Tools for Brain-Computer Interfaces Workshop, Graz. Feb. 2010.

[15] P. J. McCullagh, M. P. Ware, G. Lightbody, M.D. Mulvenna, H. G. McAllister, C. D. Nugent "Brain Computer Interfaces for Inclusion", Proc. of the 1st Augmented Human Int. Conf. Megève, France, 2010.

[16] G. Garcia-Molina, D. Ibanez, V. Mihajlovic, and D. Chestakov, "Detection of High Frequency Steady State Visual Evoked Potentials for Brain-Computer Interfaces,", in Proc. EUSIPCO 2009 conference, August 2009, pp648-650.

[17] O. Frimann, I. Volysak, A, Gräser "Multiple channel detection of steady-state visually evoked potentials for brain-computer interfaces", IEEE Trans. On Biomedical Engineering, Vol 54, No 4, Apr. 2007, pp742-750.

[18] P. J. Durka, openBCI. University of Warsaw, Zakład Fizyki Biomedycznej, Hoża 69, 00-681 Warszawa, Polska. Available: http://bci.fuw.edu.pl/wiki/Main Page

[19] R. Adams, G. S. Bahr, B. Moreno, "Brain-computer interfaces: Psychology and pragmatic perspectives for the future", Online Proc. of the Convention of the Soc. For the Study of Artificial Intelligence and Simulation of Behaviour 2008.

[20] S. Parini, L. Maggi, A. C. Turconi, G. Andreoni, "A robust and selfpaced BCI system based upon a four class SSVEP paradigm: Algorithms and protocols for a high-trnasfer-rate direct brain communication", Computational Intelligence and Neuroscience, Apr. 2009, Hindawi Publishing Corporation.

[21] C. Mauri, T Granollers, A. Solanas, "On the Assessment of the Interaction Quality of Users with Cerebral Palsy", $2^{\text {nd }}$. Intl. Conf. on Availability, Reliability and Security 2007.

[22] S. G. Mason, M. M. Moore Jackson, G. E. Birch, "A General Framework for Characterizing Studies of Brain Interface Technology" in Annuls of Biomedical Engineering' vol. 33, no 11, Nov. 2005, pp1653-1670. 